\title{
Después del genocidio. Registros y memorias territorializadas en Pulmarí, Neuquén
}

(4) Alexis Papazian*

Fecha de recepción: 10 de septiembre de 2018. Fecha de aceptación: 20 de julio de 2019

Palabras clave

posgenocidio territorialización memorias mapuche registros estatales

\section{Resumen}

Este artículo analiza un proceso de (des)territorialización en la provincia de Neuquén, relacionado con el genocidio contra la población mapuche iniciado hacia fines de siglo XIX. Nos interesa observar los corrimientos territoriales en períodos posteriores a la conquista militar sobre la Patagonia. En este sentido, tomaremos el proceso de despojo de población mapuche dentro del Parque Nacional Lanín en la década de 1950. Los objetivos son: repensar las prácticas posgenocidas habilitadas tras la violencia de la conquista del siglo XIX; observar la importancia del territorio como elemento constituyente del Estado y de la identidad mapuche y analizar las memorias sociales sobre territorios mapuche en relación con las formas de resistencia indígena. Para ello, trabajamos con registros, memorias editadas y fichas de población generados por Parques Nacionales y también con la memoria social de actuales pobladores y familias mapuche que viven en el departamento de Aluminé.

\section{After the genocide. Documents and territorialized memories in Pulmari, Neuquén Province}

\section{Abstract}

Key words

post-genocide territorialization Mapuche's memories State's documents
This paper analyzes a process of (de)territorialization in Neuquén province, Argentina, in the context of the genocide perpetrated against Mapuche people during late $19^{\text {th }}$ century. We aim to observe the territorial movements that occurred after the military conquest over the Patagonia region by tracing the dispossession the Mapuche people suffered within the National Park during the 1950s. The objectives are to rethink about post-genocide practices enabled by the violence of military conquest in the $19^{\text {th }}$ century; to analyze the role of the territory as key element in the constitution of both the State and the Mapuche identity; and to analyze the social memories referring to the Mapuche territory in relation to indigenous resistance. We will examine records, edited reports and population files produced by the National Parks State Agency, as well as

* Instituto de Ciencias Antropológicas (ICA), Facultad de Filisofía y Letras (FFyL), Universidad de Buenos Aires (UBA). Buenos Aires, Argentina. E-mail: alexis_papazian@yahoo.com.ar 
the social memory based on testimonies of settlers and Mapuche families that live in Aluminé department nowadays.

\section{Introducción}

Entre 1882 y 1883, en la región del actual Departamento de Aluminé las tropas del Ejército Argentino, a cargo del General Villegas y comandadas en la zona por el General de Brigada Rufino Ortega y por el Teniente Coronel Enrique Godoy, realizaron la avanzada sobre el llamado triángulo del Neuquén. Ortega partió desde el fuerte de Ñorquín, mientras que Godoy lo hizo desde Choele Choel alcanzando la zona de Aluminé y teniendo como límite el piedemonte andino, futura divisoria con la República de Chile que, de forma concertada, realizaba con su ejército el avance sobre la frontera de la actual región de Araucanía.

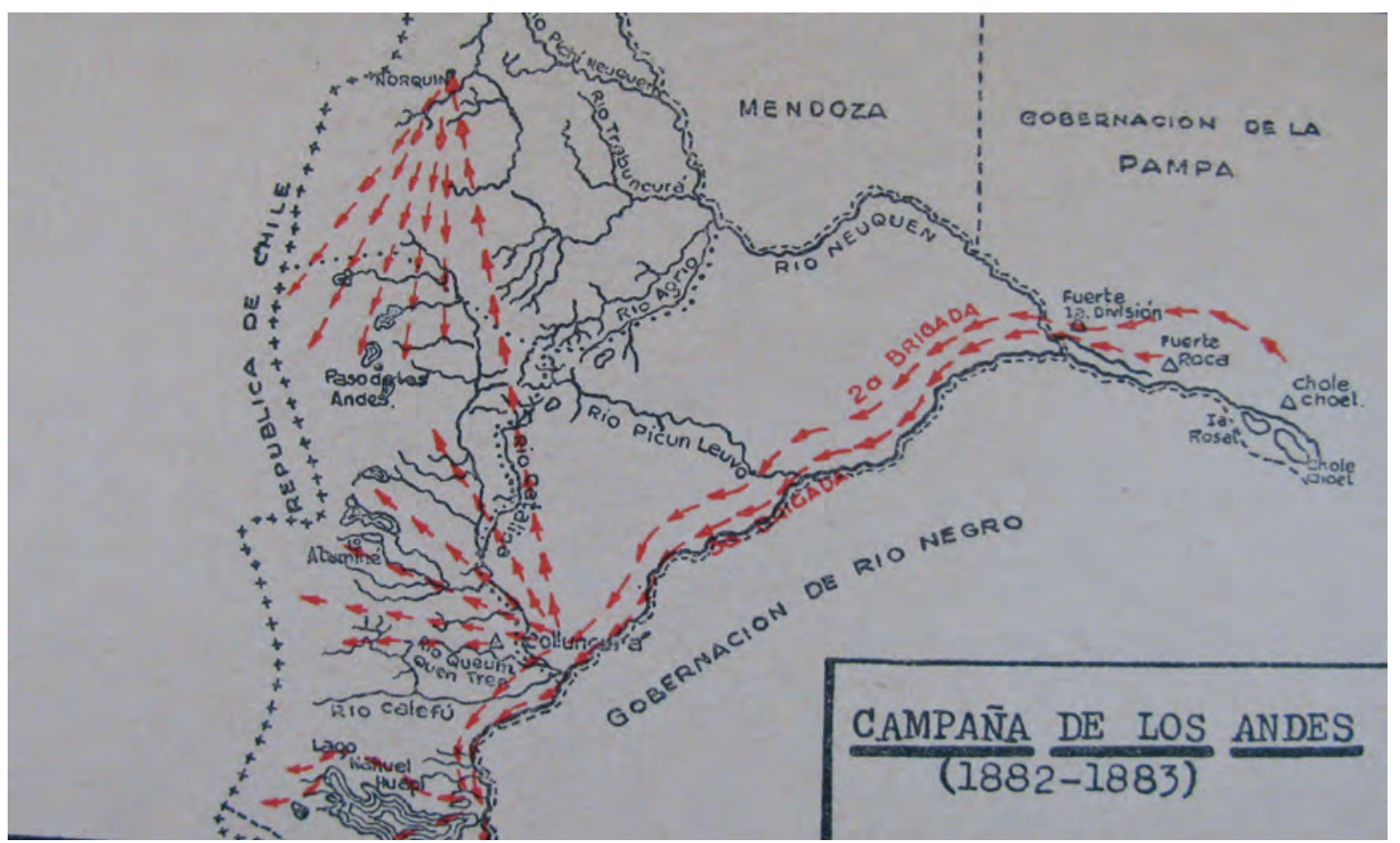

Croquis 1. La Campaña a los Andes. Extraído de Figuerero (1945).

El resultado de este avance fue un primer movimiento desterritorializador ${ }^{1}$ con el consecuente vaciamiento de población indígena, que en un número superior al de 3000 personas, fue capturada y enviada a Buenos Aires o a las fincas del propio Rufino Ortega en Mendoza (Escolar y Saldi, 2018: 99-136). Esta política de erradicación y esclavización de indígenas visualizó, sobre todo, a importantes líderes mapuche como Reuque Curá; sin embargo, la mayor cantidad de víctimas fueron mujeres, niños y niñas que eran parte de las comunidades de la región o de otras parcialidades que se habían refugiado en la zona viniendo desde el actual Chile o desde la zona pampeano-bonaerense.

Aunque el objetivo de este trabajo no es analizar las prácticas genocidas a nivel general ni regional, sí queremos dejar planteada esta situación de inicio dado que es un parte-aguas en la historia mapuche. Vale la pena citar un breve pasaje de Francisco Moreno ([1897]) 2004) que remite a la región de Aluminé/Pulmarí, la cual visitó como explorador y como perito de Estado. Moreno describe:
1. Por desterritorialización entendemos todo proceso violento, o no, que se manifiesta de forma física y simbólica y tiende a borrar y/o negar una forma de territorialidad previa para, de forma simultánea, reconfigurar un territorio determinado de forma arbitraria, modificando a futuro la comprensión del mismo y generando nuevos paisajes de poder y resistencia. (Véase Haesbaert, 2011: 85-117). Los procesos desterritorializadores en el contexto de las "campañas contra el indio" tuvieron graves consecuencias que pueden rastrearse hasta nuestros días, como las formas en que los sectores y organizaciones indígenas son "marcadas", en muchos casos, como extranjeras y/o falaces (Lenton, 2017; Papazian, 2013). 
2. Ciertamente hay conceptualizaciones diversas sobre el término genocidio. Bjornlund et al., (2005: 17-48), observan las diferentes disciplinas y perspectivas en torno al campo de estudios de genocidio. Estos autores observan perspectivas que solo piensan al Holocausto como única experiencia genocida hasta terminologías excesivamente inclusivas como las que asimilan los crímenes en masa con los genocidios. Los autores observan ciertas problemáticas legales que imposibilitan pensar a los Genocidios por fuera de los marcos jurídicos regulatorios; sin embargo, las ciencias sociales han generado nuevas interpretaciones en torno al concepto genocidio que nos permite observar un largo devenir en las prácticas genocidas: desde prácticas previas -discriminación, creación y marcación del grupo en tanto negativo-, formas de sojuzgamiento y debilitamiento sistemático, para pasar a la eliminación física del grupo -sin importar la persona víctima- y una posterior justificación o negación o invisibilización del crimen (Feierstein, 2007). (continúa en página 93).

3. En diversas visitas en la región hemos2 podido conocer "contadas" en torno a la batalla de Pulmarí; desde la épica del ejército argentino hasta las formas de resistencias mapuche en un contexto de avance estatal. En el camino entre Pulmarí y Ñorquinco se encuentra el monolito al cual referimos en el cuerpo del texto. Vale también mencionar que en el pueblo de Aluminé tanto el teniente Lezcano como el capitán Crouzeilles tienen su lugar, en calles que llevan su nombre.

4. Entendemos por procesos posgenocidas a aquellos que habilitan nuevas formas de violencia fáctica y simbólica sobre los grupos marcados por un genocidio pretérito. La particularidad de una violencia posgenocida radica -al igual que en los genocidios- en que los victimarios caracterizan a las víctimas, marcando una diferencia cualitativa de la violencia cuando los sujetos violentados son presentados como una amenaza colectiva. En este sentido los pueblos originarios, en general, y los mapuche, en particular, han sido depositarios de una serie de atributos negativos rastreables desde mediados del siglo XIX hasta nuestros días. Esto no anula una serie de acciones tendientes a revertir este proceso, conformando el todo una pugna de los sentidos que adquiere el carácter de resistencia y/o agencia.

5. ADPC. Neuquén. Dup N¹6, f. 23. la Vega de Pulmarí, verdadera tierra de promisión [...donde], nos dirigimos al oeste para conocer las vegas de Ñorquincó, de renombre por su hermosura y en cuyas inmediaciones se ha dado principio a la demarcación de la frontera con Chile. Esa región de Pulmarí y sus alrededores es una de las más hermosas que he visto en mi vida, y bien aprovechada por la Nación sería, a no dudarlo, en breve tiempo un centro de actividad si la colonización se hiciera con elementos que correspondan al suelo [...] El pasado, la inanidad humana, la encontramos en las blancas calaveras y en los huesos destrozados de un cementerio indígena revuelto por los buscadores de prendas de plata, y pasado este cuadro lúgubre penetramos en una hermosísima llanura, donde hubiéramos querido encontrar la lechería que completaría aquel marco encantador [...]. Allí flameó la bandera querida, en el avance duro de nuestros soldados, cumpliendo el deber sagrado de defender a la patria... Allí están las tumbas de los lanceados por el salvaje, en sus luchas de cien contra uno. ¡Pobre milico! Tu sacrificio anónimo no ha dado aún resultado y ya ha sido olvidado.... (Moreno, [1897] 2004: 61-63).

Esta cita piensa y crea al territorio desde una época específica; sin embargo, bien vale llamar la atención sobre la actualidad que aún en nuestros días tienen ideas de este tipo donde la imagen del progreso -los recursos "estratégicos"actúa como un sello de validez ante nuevas prácticas de despojo. Moreno territorializa con sus palabras parte de la concepción del disfrute y del recurso económico, pero dando por sobreentendido una forma homogénea de crear un territorio, dominado y controlado por el Estado (Sack, 1983). La ausencia del salvaje está en "sus blancas calaveras". El genocidio ${ }^{2}$ actúa en planos reales y simbólicos. Los soldados lanceados son nulos o pocos en los registros y partes del Ejército, mientras que los indígenas muertos se cuentan de a cientos y los prisioneros de a miles (Villegas, [1881-1883] 1977).

Los lugares de memoria oficial se materializan desde el Estado, en un monolito y mástil con la insignia patria. La "batalla de Pulmarí", ocurrida el 6 de enero de $1883^{3}$ está presente en el Territorio-Estado; en ella pierden la vida varios indígenas pero sólo los nombres del capitán Crouzeilles y el Teniente Lezcano son recordados. Queda la memoria de los mapuche pero marginal y silenciada como aquellas calaveras que Moreno describe.

El territorio se configura terror en dos planos; la imagen creada de los indígenas y las experiencias sufridas por ellos se alejan del pasado y se proyectan sobre el futuro, de ahí la importancia de pensar procesos pos-conquista genocidas como procesos posgenocidas. ${ }^{4}$

En un informe de mensura de Pulmarí, el agrimensor Emilio Candiani menciona como "el terror de la conquista ha producido tal impresión en el ánimo del indígena que por espacio de muchos años no ha aparecido más en aquellos parajes sino para cosechar la fruta del pino". ${ }^{5}$ Los cementerios revueltos, las casas volteadas, la invisibilización comunitaria se vuelve inmanente en los procesos posgenocidas, más aún cuando el genocidio de origen no se reconoce.

Pensemos en la proyección de Francisco Moreno en términos naturales y económicos, pero también en términos políticos y territoriales. Es el progreso territorializador que vive en el imaginario argentino contra las marcas primitivas y externas de lo indígena.

Volvamos al plano histórico. Finalizado el avance militar las extensiones de tierra conquistadas comenzaron a ser concesionadas a privados, en mayor 
parte extranjeros europeos. La familia Miles se benefició, en 1892, con una concesión de 80.000 hectáreas con el objeto de crear dos poblados a las orillas del río Pulmarí (Papazian, 2013). Esta proyección llegó a tener planos aprobados pero nunca concretó la entrega de tierras a colonos, ni la construcción de dichos pueblos.

A los pocos años, la familia Miles consigue que la concesión se redefina como ganadera. Nace así la Compañía Estancia Pulmarí Ltd. que dejará de operar en 1947, tras la firma de un decreto de expropiación a partir del cual el espacio territorial se modifica de forma sensible provocando nuevos procesos de enajenación y despojo indígena.

\section{El Parque Nacional Lanín y su proceso de reorganización poblacional}

En 1937, por medio del Decreto 105.433 se establecieron diferentes territorios patagónico-andinos en condición de reservas. Al año siguiente, el Decreto 125.596 estableció los límites del actual Parque Nacional Lanín (PNL) que fueron redefinidos en abril de 1945 y ratificados por la Ley 13.895 de 1949. A su vez, el 14 de junio de 1947 se publicó el Decreto 16.830/47 el cual expropiaba la Compañía Estancia Pulmarí a favor del Poder Ejecutivo Nacional, que entregó dichas tierras a la Administración del PNL. En síntesis, entre1947 y 1952 el área del PNL incorporó casi 80.000 hectáreas en su región norte, dicho espacio fue conocido como Anexo Pulmarí y hacia fines de 1952 este espacio territorial fue entregado al Ejército Argentino.

Durante el lapso en que el PNL gestionó Pulmarí se dieron procesos de reubicación/desalojo; creemos conveniente observar algunos puntos constitutivos y constituyentes de Parques.

Parques Nacionales ubica al ya mencionado Moreno como mentor de dicha institución. La Ley 12.103 crea la Dirección de Parques Nacionales, organismo encargado de administrar el Parque Nacional Nahuel Huapi -otrora Parque Nacional del Sud- y el Parque Nacional Iguazú. Dentro de las atribuciones de esta dirección resaltamos la entrega de concesiones, la obligación de realizar censos de población, proceder a desalojos que "a su juicio no convengan a los intereses de Parques", conservar y cuidar los bosques nativos, entregar arrendamientos y/o títulos precarios, entre otras facultades. ${ }^{6}$

El PNL se crea en 1945 por medio de la Ley 13.895. Bruno Carpinetti (2004), quien analizó las políticas de Parques desde los momentos de su conformación, observaba que la promulgación de la Ley de Parques de 1934 y la posterior creación del PNL:

define que las tierras bajo esta nueva jurisdicción son inalienables y sujetas a dominio público. En los años subsiguientes, los efectos de la ley provocan la reubicación de comunidades que previamente vivían dentro de los límites del nuevo parque como las Ñorquinco y Aigo. Desde su misma concepción, el Parque Nacional Lanín adquiere el carácter de una entidad político-territorial nacional, respondiendo a una estrategia de ocupación basada principalmente en el asentamiento de villas orientadas al desarrollo de la actividad turística. (2004: 39-40).
6. AGN. DSCS, Biblioteca Central 1934: 1018. 
7. Artículo 11 de la Ley 12.103 en AGN. DSCD, Biblioteca Central 1934: 1017 .

8. Decreto Ley 15.385 de creación de la CNZS. Citas y síntesis de los Arts. $1^{\circ}, 2^{\circ}, 4^{\circ}, 7^{\circ}$ y $9^{\circ}$. Disponible en Internet: http://www.mininterior. gov.ar/fronteras/sol_archivos/normativas/Decreto-Ley15385-44.pdf. Consultado el: 26 de abril de 2018 . Véase también Muzzopappa (2000: 38-43).

9. APN. Programa Pobladores y Comunidades. "Fichas de pobladores. Anexo Pulmarí”.
El término "reubicación" implica volver a colocar en "su lugar" y es un tipo verbal reflexivo, al punto que uno mismo -o un conjunto social- podría "reubicarse" por decisión propia. No es este el caso, es decir el accionar de Parques se equipara al de desalojo, situación observada de manera recurrente en diversas regiones administradas por Parques (Valverde et al., 2008; Valverde, 2009: 74-90; Bessera, 2011: 67-106; Trentini, 2011: 161-194; Tozzini, 2011: 275-305). Desde este punto de vista, tanto las formas en la que las experiencias son narradas, como los registros escritos de la APN (Administración de Parques Nacionales) describen el accionar como una práctica legalizada, necesaria y racional; lo que se observa como ausente es la práctica en sí y la violencia que encierra.

Los documentos estatales sólo registran desalojos de indígenas, chilenos o indígenas-chilenos; entendiendo que Parques hizo valer el “...deber principal de la dirección, de desarrollar en ellos [los parques nacionales] una constante política de nacionalización", 7 equiparando la condición de pre-existente a la de extranjero, situación observable hasta nuestros días.

De forma paralela es importante dar cuenta del rol de la Comisión Nacional de Zonas de Seguridad (CNZS), creada en 1944, pues todo el PNL y el Anexo Pulmarí, en particular, se encuentran en zonas de frontera. La CNZS “ejercerá en dicha zona la policía de radicación con relación a la transmisiones de dominio, arrendamiento o locaciones, o cualquier forma de derechos reales o personales $[\ldots]$ a cuyo efecto acordará o denegará las autorizaciones correspondientes". También podrá, mediante decreto del Poder Ejecutivo, expropiar bienes que se encuentren dentro de las zonas de seguridad y resolver pedidos relativos a la explotación de servicios públicos, transporte, energía, entre otros. ${ }^{8}$

Analizar las modificaciones jurídicas implica analizar las modificaciones territoriales. Siguiendo a Lefebvre ([1974]) 2008) se desprende la importancia del dominio del espacio y el tiempo como fuente de poder social. Desde esta perspectiva Harvey ([1990] 2012) llama la atención sobre la problemática que encierra comprender las luchas sociales entrelazadas en una dialéctica que incluye al territorio/lugar y al tiempo como ejes no estáticos y políticamente activos (Harvey, [1990] 2012: 251-266).

\section{Gobernar es despoblar}

En 1947 se firmaba en Buenos Aires el decreto de expropiación de la Estancia Pulmarí; a partir del mismo comenzaba en el PNL un proyecto de reasentamiento de población mapuche que vivía dentro del parque. Este proyecto necesitó, en inicio, de un censo que quedó registrado en fichas de pobladores que luego serían enviadas al Anexo Pulmarí. ${ }^{9}$ Todas estas fichas poseen datos referidos a los pobladores dentro del PNL, la cantidad de ganado y las resoluciones sobre permisos, traslados o desalojos dentro del área del PNL hasta 1953, año en el que el Anexo Pulmarí pasa al Ejército nacional.

La mayor parte de las fichas corresponden a pobladores -y familias-, ocupantes precarios de fracciones o lotes dentro del PNL; solo en pocas oportunidades se los cataloga como "chilenos" y en las fichas no figura la pertenencia étnica o racial. A partir del trabajo de campo podemos aseverar que la adscripción étnica de estas familias es mapuche. Por su parte, algunas fichas mencionan a la tribu de Juan Aigo y la de Francisco Curruhuinca. Pudimos identificar, como mínimo, un total de 51 familias mapuche -un total superior a 350 personas entre mujeres, hombres, niñas y niños. Algunas de estas familias eran parte 
de las comunidades actuales Aigo, Catalán, Curruhuinca, Currumil, Salazar y, mayoritariamente, Norquinco. ${ }^{10}$

El decreto 16.830, firmado el 14 de junio de 1947, aprobó:

la adquisición de la Estancia "Pulmarí" efectuada por el Presidente de la Comisión Nacional de Zonas de Seguridad, en el remate realizado por Adolfo Bullrich y Cía. Ltda. S.A. el 14 de mayo ppdo [...] refrendado por los Sres. Ministros Secretarios de Estado en los Departamentos de Interior y Guerra. Fd. Juan D. Perón, Presidente de la Nación; A. G. Borlengui; Humberto Sosa Molina. ${ }^{11}$

El decreto 29.634, establece que el presidente de la CNZS:

firmará en nombre del Gobierno de la Nación la escritura traslativa de dominio, libre de todo gravamen correspondiente a la adquisición de la Estancia 'Pulmarí'; [...] Una vez firmada la escritura traslativa de dominio, la Comisión Nacional de Zonas de Seguridad hará entrega, a la Adm. Gral. de Parques Nacionales y Turismo, de la Estancia 'Pulmarí para su cuidado, conservación y utilización $[\ldots]^{12}$

Cuando la APN se hace cargo de la estancia comienza el proceso de radicación de pobladores dentro del Anexo Pulmarí. El 16 de junio de 1948 la resolución 13416 ordena: "destinar las superficies aptas para pastoreo, ya sea de invierno y/o de verano, para la radicación de pobladores de las zonas boscosas de otros Parques Nacionales"13

En noviembre de 1948, se emite la resolución 15.490 en la cual se autoriza a la intendencia del PNL:

a trasladar paulatinamente al Campo Pulmarí, y a medida que se cuente con las casas que a tal efecto irá construyendo la Administración en las zonas eminentemente pastoriles, a los pobladores de su jurisdicción cuya nómina se consigna a fs. 4/6 del Expediente $N^{\circ} 11729-948 .{ }^{14}$

Estos decretos y las resoluciones posteriores clarifican el escenario jurisdiccional dentro de Pulmarí, que de estancia de los ingleses deviene en campo expropiado entregado a la APN que lo utiliza para radicar a pobladores que viven en el PNL. En la mayor parte de las fichas se consignan resoluciones que implican la entrega de Permisos Precarios de Ocupación y Pastoreo (PPOP) en años previos a 1947. Estos permisos quedarán sin efecto y, en noviembre de 1948, queda: "vedado en lo sucesivo introducir animales en cualquier otra tierra de la jurisdicción del Parque Nacional Lanín".

El Anexo Pulmarí es, en este caso como en tantos otros, lugar de (des)territorialización temporal pues en los inicios de la década del 1950 la antigua estancia pasará a manos del Ejército Nacional. La mayoría de los casos relevados están reglados por entregas de PPOP en lugares de origen -generalmente fuera de la región de Pulmarí y dentro del PNL-, luego inhabilitaciones y traslados coactivos hacia la región de Pulmarí -traslados que muchas veces quedan inconclusos, manifestando sólo el desalojo pero no el arribo a Pulmarí- para, finalmente, volver a desalojar -ahora en Pulmarí- a las familias trasladadas al Anexo.
10. APN. Programa Pobladores y Comunidades. "Fichas de pobladores. Anexo Pulmarí". Nómina de pobladores mapuche es: 1 . Ancafil, Mariano/ 2. Aigo, Juan; AngelaCaytrú y cinco miembros más/ 3. Antigual, Rosa; José Miguel Antigual y siete miembros más/ 4. Antin, Manuel; Tránsito F. de Antin y cinco hijos/ 5. Barriga, Florindo; Juana Curipan y nueve hijos/ 6. Barriga Ramón; María M. N. de Barriga y nueve hijos/ 7. Bravo, Romualdo (sucesión) y Petrona Millapán/ 8. Catrileu, Rosa Nélida/ 9. Catrileu, José Aniceto y diez pobladores más/ 10. Ñanco, Miguela (viuda de Calfunahuel) y siete hijos/ 11. Catrileo, Francisco/ 12. Caitrúz, Juan Angel/ 13. Caitrus, Mauricio/ 14. Caitruz, Nastacio/ 15. Catalán, José Nicasio; María L. de Catalán y seis pobladores más/ 16. Chávez, Andrés; Candelario Huentina y tres hijos/ 17. Cañicul Francisco; María Llanquín y tres hijos/ 18. Cañicul, Valentín; Amelia Curinao y cuatro hijos/ 19 Cifuentes, José Pascual/ 20 Contreras, Nicanor/ 21. Contreras, Marcelino/ 22. Gil, Bautista/ 23. Huietra, Sabina; Carmera Catricura y cinco pobladoras más/ 24. Huenchufil, Manuel/25. Huichaqueo, Manuel/26. Huicahqueo, Rogelio/ 27. Isla, Ramón/ 28. Lefiche, Francisco/ 29. Lican, Andrés/ 30. Llancafilo, Francisco/ 31. Mariñanco, Aurelio; Micaela Huechaqueo y siete hijos/ 32. Morales, José; Matilde Cayún y nueve hijos/ 33. Marril, Fidel; Petronila Jaramillo y siete hijos/34. Miñañanco, Avelino; Manuela Catrileo y cinco hijos/35. Millalaf, Juan/ 36. Ñanco, Eduardo; Juana Ñanco y tres hijos/ 37. Ñanco, Juan José/ 38. Nanco, Vicente/ 39. Ñanco, Manuela/ 40. Painillan, Manuel/ 41. Panguilef, Eusebio; BrauliaQuilapán y cinco pobladores más/ 42. Quintonahuel, Fidelia/ 43. Quilapán, José y siete pobladores/ 44. Quirulef, Manuel/ 45. Romero, Gervasio/ 46. Romero, Margarita (viuda de)/ 47. Reyes, Gilberto/ 48. Salazar Albino/ 49. Salazar, José Heraldo/ 50. Soto Muñoz, Hilario/ 51. Aigo, Francisco.

11. Copia del decreto 16.830. 14/06/1947. APN. Programa Pobladores y Comunidades. Fichas de pobladores. Ficha General.

12. Copia del decreto 29634. 25/og/1947. APN. Programa Pobladores y Comunidades. Fichas de pobladores. Ficha General.

13. APN. Res. 13416. Programa Pobladores y Comunidades. Fichas de pobladores.

14. APN. Res. 15490. 04/11/1948. Programa Pobladores y Comunidades. Fichas de pobladores. 
15. APN. Memoria General 1948 (1949: 8).

16. APN. Memoria General 1948 (1949: 9 y ss).
Ahora bien, si basamos nuestros estudios en las Memorias Generales que la APN publica anualmente observamos que la identidad que Parques construye de sí mismo incluye una épica al marcar obstáculos, desafíos y logros a partir de la adquisición "del campo denominado Pulmarí, [...] Entregado a la Repartición para su cuidado y utilización existen, en el mismo, mejoras de importancia en alambrados, poblaciones y construcciones generales (1948: 12).

[En el Anexo Pulmarí] se construyeron nuevas casas para empleados y en las existentes se construyeron cercos, tranqueras, alambrados [...]. Se construyeron muelles y puentes y...comenzaron los trabajos preparatorios para acoger a los pobladores desalojados de otros parques en defensa de la milenaria riqueza de los bosques de la Patagonia. Se ha instalado en la vieja estancia un encargado y se tomó inventario de lo existente comenzándose las construcciones y los estudios camineros y de otra naturaleza. ${ }^{15}$ (1948: s/n)

En otras palabras, la adquisición de Pulmarí explicita la necesidad de desalojar para cuidar la milenaria riqueza de los bosques de la Patagonia. Sin embargo, los desalojos serán en casi todos los casos contra población mapuche y de forma alguna contra los grandes propietarios que poseen -hasta hoy día- grandes y lujosas casas dentro de los límites del Parque.

La Memoria General correspondiente al año 1948 especificará con mayor atención la importancia de la adquisición del Anexo Pulmarí, partiendo de la Ley 13.444 que declara de utilidad pública las propiedades privadas dentro de Parques:

Esta importantísima medida de gobiernos hará por fin accesible al estudioso, al hombre de ciencia, al turista y al pueblo en general, todos los lugares de los distintos parques nacionales, suprimiéndose la restricción que imponían las propiedades particulares, en algunas zonas señaladamente bellas. ${ }^{16}$

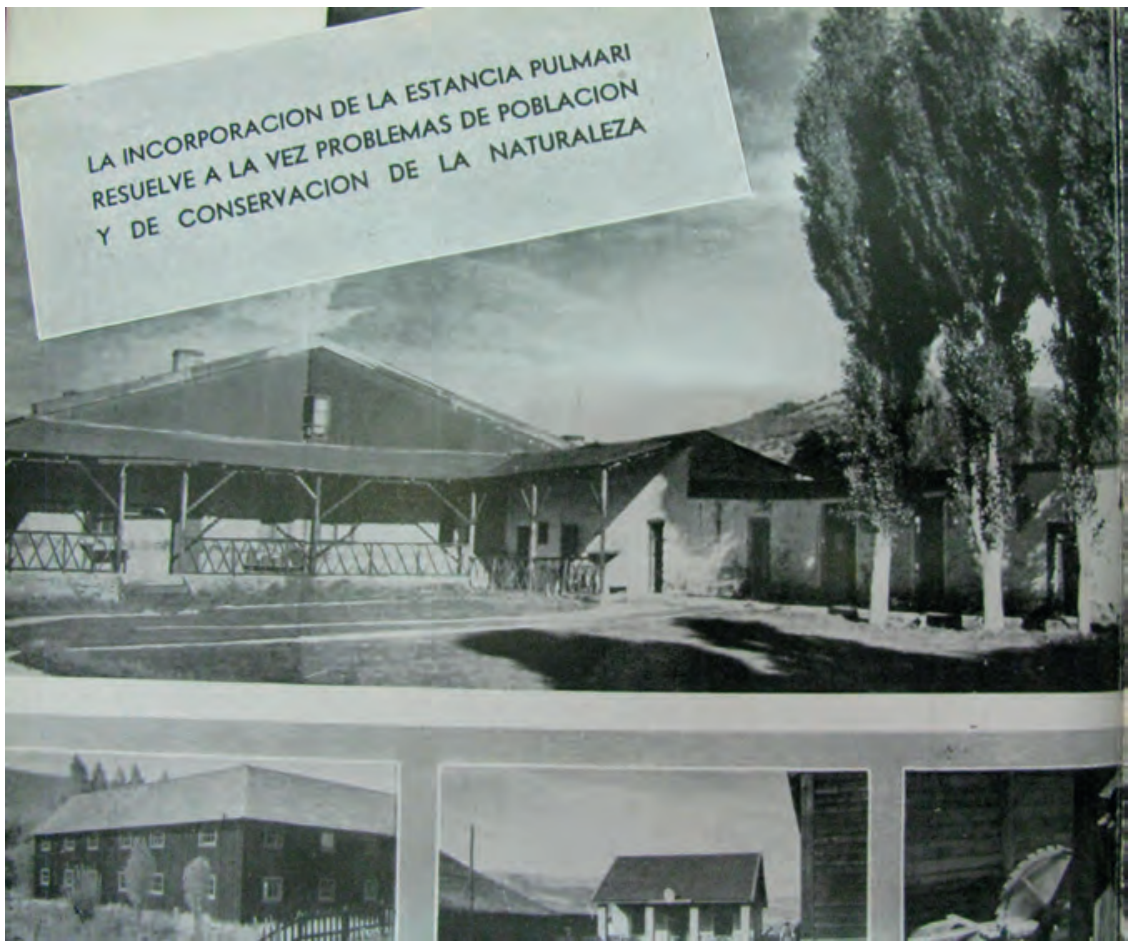

Imagen 1. Memorias de Parques Nacionales. La incorporación del Anexo Pulmarí. (APN, 1949: s/n). 
Las ilustraciones -Imagen 1- que acompañan la adquisición de la antigua estancia dan cuenta de la importancia y el éxito que posee esta política, pues "resuelve a la vez problemas de población y de conservación de la naturaleza" (1949: s/n). El epígrafe central explica el progreso en la región:

permitiendo a la vez la absorción de los pobladores de otros parques nacionales que deben ser desalojados para el cumplimiento de la política conservacionista. El gobierno nacional ha tenido en cuenta así el problema humano de los pobladores, a los que brinda amplio lugar para el desarrollo de sus posibilidades de vida y progreso. ${ }^{17}$

Parques es contundente: los pobladores deben ser desalojados para el cumplimiento de la política conservacionista. La Memoria correspondiente al año 1949 titula el éxito de la política de traslados bajo la frase "NUMEROSOS POBLADORES FUERON TRASLADADOS AL ANEXO PULMARI'". La foto que encabeza la página da cuenta del tamaño importante de los "REBAÑOS DE OVEJAS, que perjudicaban a la riqueza forestal, dentro de los parques, y que se desarrollan ahora libremente en el Anexo". De manera similar se resalta la importancia de "EQUINOS DE TRABAJO, que se crían en el Anexo". El epígrafe central de esta página sintetiza el éxito político de estas medidas pues: [...] La preservación de la naturaleza se cumple así, sin perjuicio de intereses humanos, de acuerdo con los postulados sociales del General Perón. (1950: s/n)

De forma contraria, sostenemos en este trabajo que el desalojo compulsivo y obligado de mapuches es parte de los procesos posgenocidas en los que el territorio -en tanto espacio controlado por el estado y transitado y construido por las sociedades- entra en disputas que, lejos de ser coyunturales, se entroncan en un proceso de amplio alcance. El territorio se construye entonces a partir de violencias, traumas, desalojos, pero también de afectos, vivencias y experiencias locales (Haesbaert, 2011).

El lector de las Memorias de Parques podrá observar los beneficios de las políticas conservacionistas en coherencia con la defensa de los peones rurales "reubicados"; sin embargo, esto es lo que Deleuze y Guattari (1997) definen como un lenguaje de obediencia.

Esto se constata con toda claridad en los comunicados de la policía o del gobierno, que se preocupan muy poco de la credibilidad o de la veracidad, pero dicen muy claro lo que debe ser observado y retenido [...] El lenguaje no es la vida, el lenguaje da órdenes a la vida; la vida no habla, la vida escucha y espera. (Deleuze y Guattari, 1997: 81-82).

Los documentos estatales nos dan una pequeña sentencia que debemos obedecer; una orden que señala que los pobladores perjudican el medio natural de un Parque Nacional, por lo tanto se los debe "reubicar". Pero está, también, "la vida [que] escucha y espera". De ahí la resistencia localizada de las memorias sociales, que siendo (in)asibles al discurso estatal se escapan del registro fijo. ${ }^{18}$

\section{Territorio-cuerpo. Territorio-memoria}

Las memorias locales poseen una potencia diferente al momento de interrelacionarlas con otro tipo de registros. Se ha observado que las memorias tienen una menor capacidad de exteriorización y traslación, pero poseen una fuerza espacializada en el afecto colectivo y en la historia (Papazian, 2009; 2011a; 2013).
17. APN. Memoria General (1949: $s / n)$.

18. Siguiendo a Stuart Hall (1986), las resistencias son entendidas como parte de un todo inserto en un proceso hegemónico/contrahegemónico. En este punto, las memorias locales en su condición de inicio son memorias agenciadas de forma afectiva (Ramos, 2010), dando un lógica que, en contextos conflictivos, escapan al aparato estatal siendo las mismas comprensibles dentro de experiencias sociales que cimentan en el proceso de comunalización (Brow, 1990). Dicho esto, comprendemos las resistencias y las agencias como líneas de fuga que movilizan en presente comprimiendo tiempo y espacio y generando nuevas formas de acción que nada tienen que ver con la mera repetición, sino que se proyectan al futuro (Deleuze y Guattari, 1997: 9-32). 
19. Fragmento de una entrevista realizada durante el trabajo de campo, 14 de enero de 2009. Miembro del lof Norquinco. quinco, 14 de enero de 2009.
En este apartado trabajaremos la vinculación de las memorias locales con las prácticas descriptas en los documentos mencionados. Nos centraremos en la comunidad de Aniceto Catrileo -actualmente comunidad Ñorquinco- que se conforma tras el avance militar en la región y a partir de los procesos de radicación y familiarización posgenocidio, a inicios del siglo XX. Es a partir de estos traslados que las comunidades se asientan y reorganizan en la región alrededor de la figura de Aniceto Catrileo, lonko histórico que tendrá vigencia hasta mediados del siglo XX cuando Parques irrumpe en la zona provocando la desestructuración de la comunidad con sus políticas de traslados. Recién a fines de la década del 1990 del siglo XX, la comunidad reemergió con su actual nombre: Norquinco.

En una entrevista realizada a Ana Sepúlveda, en la actual comunidad Ñorquinco, pudimos hablar del proceso vivido en la década de 1950. Iniciada la charla, mate en mano, Ana contaba que su familia fue siempre de la zona desde la época de su abuela, Tránsito Contreras.

yo no aprendí de tonta a hablar mapuche [...] mi abuela sí, sabía; comíamos muday, harina de piñón hacemos, cuando no había carne comíamos eso, catuto de piñón, enteritos, cocidos [...] De niña íbamos a la escuela [...] y mi abuela salía todas las mañanas a rogar, una rogativa, tiraba un poquito de yerba, un poquito de todo. Se pedía permiso a todo. A la mañana temprano [...] no tomaba el mate así nomás [...] el primer mate para la mapu [tierra], pedía pues [...] así yo me crié. [Aniceto Catrileo...] fue un lonko [líder] importante, el rehue [lugar de ceremonias] está al otro lado [...] está dentro de lo que hoy es Parques y la Comunidad [...] porque eso era que vivían acá [...] está la tapera de él [por el lonko]. Tenía como 11 años cuando iba al gnillatún [rogativas ceremoniales] y ahora tengo 82. El rehue está, queda enfrente del puente, arriba hay una pampa, y ahí está el rehue [...] ahora no se hace el gnillatún [...] Cuando la recuperación [mediados de la década de 1990] se hizo la ceremonia [...] vinieron muchos lonkos, vino Antonio Salazar, Elías Maripán [.... ${ }^{19}$

El valor afectivo que adquiere el territorio en el relato de Ana es ante todo actual. Un valor interno, en tanto territorio capaz de cohesionar familias y prácticas culturales que se mantienen en las memorias y las recuperaciones. Mientras el valor externo de dicho afecto radica en interpelar las políticas estatales que han intentado erradicar a la población mapuche borrando las experiencias comunitarias. No es casual que la Comunidad Norquinco sea visualizada como una "nueva", cuando en términos históricos posee un pasado similar al de otras comunidades avaladas en la década del 1960 por el estado y preexistentes a dicho reconocimiento.

En otra entrevista con el lonko de la comunidad, Eloy Calfinahuel, pudimos conocer la forma en que la comunidad recordaba a Parques. Nos contaba que:

Parques Nacionales fue uno también que vino a reprimirnos, te pueden decir los abuelos que volteaban las casa a cincha, [...] en la actualidad con Parques Nacionales en la jurisdicción estamos siguiendo este escenario político de comanejo [...] también fue lucha, fue de que nuestros lonkos vayan a tomar la Intendencia en San Martín [de los Andes...] y conseguir este espacio político [...] de esa manera pudimos volver a retomar nuestros derechos; inclusive hacer viviendas, en esta comunidad no había viviendas, Parques había desarmado todo, no quedaba nada [...] pero si quedaban los nombres de las taperas, como ser Reyes, Contreras, Calfinahuel [...] y parte de estas familias han vuelto a hacer su vivienda allí adentro $[\ldots]^{20}$ 
Lo que Eloy nos cuenta es la historia de la Comunidad Norquinco pero en relación con Parques Nacionales. La memoria pliega tiempos en un mismo territorio, que no es estrictamente el mismo. Allí donde las antiguas familias fueron expulsadas hoy vuelven los mapuche a partir de un reclamo histórico, presente y futuro.

Elvira Reyes, una ñaña (anciana) de la zona nos contaba, en primera persona cómo:

Juan Angel Reyes [...] mi abuelo [...] trabajaba en la estancia, mi esposo trabajaba en la estancia también. Cuando estaban los ingleses y nosotros vivíamos acá. En la punta del lago Norquinco, del lado de Parques [...] cuando era chica. Vivíamos de los animales [...] ovejas, chivas [...] todo había, caballo, ufisa [oveja], capvra [cabra], chancho, achawval [gallinas]. Tenía todo. Tuve 6 hijos, tres hijas y tres varones $[\ldots]$ tenía dos hermanos [...ahora] soy la única $[\ldots]$

Cuando nos sacaron de acá, nos fuimos para Chile [...] con Parque Nacional nos fuimos para Chile [...] y acá no había trabajo [...] nos sacó a todos [...] gente viviente que había, limpiaron todo, todo. Te tiraban vivienda y nos volteaban la casa [...] Somos parte de la Comunidad. Yo no me olvido de hablar [... palabras en mapudungun] eso me enseñó mi abuela, que tenía que aprender bien el Mapudungun, doña Isabel Cueñoquill y ella era de acá nomas. ${ }^{21}$

Las "contadas" rompen fronteras temporales y espaciales o las ordenan de otro modo. ${ }^{22}$ La dinámica y los corrimientos generados a partir de los desalojos generan traumas que son reparados -en parte- en el regreso ligado a los afectos por el lugar y a las luchas por el reconocimiento (Papazian, 2011b).

Ana Sepúlveda también nos contó la experiencia vivida con Parques, recordando al Guarda Parques expresó:

Yaituqueo se llamaba, un paisano como nosotros, un mapuche, y sacó gente [...] sacó todo, hasta su familia [...] limpió todo, esto en el año ‘50, yo tengo un hijo que nació en el año 50; Martín, el padre de Eloy, era recién nacido cuando salimos de allá $[\ldots]$ y llegamos acá [...] él tenía 3 añitos [...] en el 53 llegamos acá. El cuñado de mi marido [...] nos dejó el lugar [...] se fue para Aluminé [...] Y muchas familias; Licán, Reyes, Gil, Calfinahuel, Sepúlveda [...] fueron tiempos feos, tuvieron que sacar todo [...] no sé como nos sacaron a todos [...] Yaituqueo, ese fue el inventor de sacar todo [...] hablaba mapuche, era tremendo [...] mi abuela no sabía hablar en castilla y mi suegra tampoco $[\ldots]$ hablaba puro mapuche. ${ }^{23}$

Ana nos devuelve a la dimensión del trauma colectivo. El tiempo está marcado por la vida de los seres queridos y el desalojo y el despojo realizado por Parques. La desestructuración comunal recordada en la figura de aquel que llevó adelante el desalojo. El desarraigo violento es una parte importante para comprender el proceso de lucha de esta comunidad. Ana se interroga diciendo no sé como nos sacaron a todos. Tal vez encontramos una respuesta tentativa en las palabras de Sara Gil, otro miembro de la Comunidad Ñorquinco. Con Sara nos encontramos en algunas oportunidades en su casa del paraje Lonko Mula. Ella nos contaba cómo los echaron de este lugar que:

le pertenecía a mi hermano, él pagaba el pastoreo a Bosques. La primera vez que nos corrieron fue con Parques, yo tenía 14 años [...] y ahora $84[\ldots]$ Tiene que haber sido para el 47 o 50 .
21. Entrevista realizada en el paraje Reyes, en la margen norte del Parque Nacional Lanín, 15 de enero de 2009.

22. Las "contadas" son un registro narrativo que nos introduce en las memorias lejanas, en las historias de los abuelos. Sin embargo, estas contadas no están ancladas en un pasado "fijo" sino que tienden a modificar sentidos en el contexto presente, en la agencia presente que no deja de enmarcarse en luchas tan históricas como vigentes. Véase Brow (1990), Grossberg (1992), Briones (1994) y Delrio (2005).

23. Fragmento de una entrevista realizada durante el trabajo de campo. Miembro del lof Ñorquinco, el 14 de enero de 2009. 
24. Fragmento de la entrevista realizada a Sara Gil en el paraje Lonko Mula, cercano al lago Pulmarí.
Y cuando nos sacaron de allá nos empezaron a repartirnos [...] hay otra casa donde vivía yo. Era al fondo para la cordillera; ve ese cerro puntudo, ese allá, ese [señalando al suroeste] le dicen Melipilun [Cuatro Orejas] ahí frente tenemos una casa. Y quedó mi nieto [...]

Mi padre se llamaba José Santos Gil, y yo Sara Gil, y mi madre Juana Casiano [...De Parques nos sacó] ese tipo era [...] extranjero de Chile, Gilberto Yaituqueo [...] inspector era [...] Nos prometía todo cosa mala, al que no podía voltear la casa, lo cinchaba a caballo para voltear la casa. Muchísimo habíamos del otro lado, yo vivía allá, ahí vivíamos nosotros, ahí donde recuperamos la tierra, donde tengo la casa, un poco más allá vivía mi tío Avelino, más arriba mi otro tío Bautista, más acá vivía Avelino Millañanco, venía de la Travesía [...] era del sur, para el lado de Zapala, de los campos, se casó con la hija del cacique, ese tipo era del sur... Cuando vino el desalojo también lo corrieron, que fueron nombrados acá son Gil, Catrileo, Licán, Reyes [...] Reyes eran los que están todavía ahí, la veranada Reyes estaba [...] Acá, al otro lado él hacía el gnillatún, hay un vado que le pusimos gnillatún [...] Cada cual saca su ramada, como ser una cantina, que ahí tiene toda la cosas [...] atienden eso a todos los que vienen de todas partes, y después empiezan a hacer la rogativa... [nos explica cómo hacer] porque cuando llega esa persona, tienen que ir a encontrar lejos y ahí hacen parlamento, de que vienen a hacer, se saludan, todo en mapuche $[\ldots]^{24}$

La contada de Sara sintetiza el devenir de muchos pobladores mapuche que, desalojados de su territorio, recorrieron un itinerario familiar en el cual el aspecto económico-laboral los incorporó como trabajadores no-calificados, siendo sus trabajos los de menor calidad, limitando sus derechos en tanto trabajadores indígenas. Se podría cuestionar si dicha situación está vinculada con la condición propia del trabajador no calificado dentro del sistema capitalista o con la condición de indígena o, como inferimos, una sumatoria de condiciones de subalternización del otro. La fluidez del recuerdo marca el rol de las familias -en el sentido amplio- y de aquellos que llegaban de otros lugares creando lazos y nuevas familias. Fluidez que permite conectar diversos aspectos de la vida cotidiana con eventos violentos de disrupción social.

Es el afecto y el trauma en el territorio lo que no sólo no se olvida sino que adquiere la verdadera dimensión de proceso social que nos permite entrevistar a personas desalojadas 60 años atrás. Ana Ramos (2010) explica la dimensión afectiva como una de las formas que adquiere el proceso hegemónico sobre la vida cotidiana:

El afecto tiene poder real sobre la diferencia, en tanto ésta sólo se realiza cuando es apropiada y sentida por las personas. Pero el afecto también participa en la configuración del espacio, puesto que, en determinados momentos históricos, activa el juego estratégico entre circular por un espacio preconfigurado o promover las líneas de movilidad. Ciertos lugares impuestos pueden transformase en nuevos lugares de apego, de compromiso y para la acción. (Ramos, 2010: 38)

Mientras la documentación estatal describe y legaliza el proceso de desalojo, las memorias nos permiten comprender una textura ligada al apego pero también al trauma generado. Las continuidades de despojo, invisibilización y desestructuración generadas desde diferentes agencias estatales no pueden comprenderse sin el proceso disruptivo del genocidio. Las contadas mapuche son actuales en tanto el genocidio es actual; son memorias que se condensan y 
articulan en narrativas histórico-políticas amplias y en procesos del presente en el que la comunalización fue y es (de)construida y (re)memorada, adquiriendo una carga política que pugna por el territorio.

\section{Conclusión}

A modo de cierre, me parece importante formular la estrategia metodológica de este artículo. En cierta medida, se buscó conjugar diferentes fuentes documentales con las memorias locales del despojo, haciendo de este escrito una muestra de trabajo interdisciplinario entre historia y antropología. Es de particular importancia remarcar que, si bien los eventos trabajados podrían situarse en la región norte del PNL hacia fines de la década del 1940 e inicios de la década de 1950, el estudio realizado nos permite observar procesos de larga duración que nos ligan con la situación presente de los pueblos originarios en nuestro país.

Buscamos realizar un análisis de corte cualitativo, observando la actualidad de ciertos procesos que, en apariencia, se ligan al pasado. Son las memorias las que resquebrajan el tiempo y el espacio y modifican la percepción de los eventos históricos. Son los documentos escritos los que nos permiten comprender el rol del estado y sus formas de justificar el accionar violento con población indígena, documentos que bien pueden "dispararse" al pasado de conquista como al presente de represión. De ahí que debamos comprender estos procesos (des)territorializadores ligados a decretos y leyes observando, como mencionáramos, un doble proceso de continuidad. El primero con la conquista y el genocidio experimentado hacia fines del siglo XIX. Es dicho avance militar el que modifica la autonomía territorial mapuche en la región, el que habilita la imagen de extinción cultural e identitaria de los/las mapuche y el que promueve una nueva construcción territorial basada en la soberanía estatal y la propiedad privada. Sobre ese pasado -relativamente cercano para la década del 1940- se habilita el despojo descripto y estudiado en este artículo. El segundo proceso de continuidad se proyecta al presente y está dado por los conflictos territoriales actuales que atraviesan la región. Las fichas de pobladores son fuentes documentales, algo así como fotografías que pierden su "fijeza" dinamizadas por el recuerdo que nuevas generaciones tienen sobre este periodo.

Este trabajo buscó dar cuenta de las formas en las que el Estado, en contextos de expansión, redujo y (des)territorializó a la población mapuche no sólo hacia fines de siglo XIX sino también en periodos posteriores. Comprender las prácticas genocidas que constituyen las estructuras profundas de los estados (Feierstein, 2007; Pérez, 2016; Delrio et al., 2018; Papazian, 2018) es permitirnos pensar en las prácticas posgenocidas. Las marcas que subalternizan sectores que son observados como amenazas, extranjeros, extintos, incapaces, entre otros adjetivos posibles, se vuelven intemporales y se activan en situaciones conflictivas. Estas formas de subalternización no niegan la agencia política a los sujetos indígenas pero sí las limitan a un espacio político marginal. El trabajo acá presentado es sólo un estudio particular en una región determinada y con un grupo de familias específicas, pero debe contextualizarse en un proceso de mayor alcance temporal y espacial observable en el presente. El accionar concreto no está en el enunciado estatal, es la diferencia/distancia narrativa del estado y su acción de "reubicación" con respecto a las memorias afectivas sobre el despojo lo se mantiene como una constante entre el genocidio constituyente y el posgenocidio posterior. Los documentos estatales y las memorias orales 
guardan correlación en fechas, nombres y lugares; sin embargo, construyen sentidos divergentes.

Sin duda alguna, la creación del Anexo Pulmarí y su devenir es, para los actuales miembros de la comunidad Norquinco, un evento epitomizante a escala local; es decir, un momento específico que sintetiza un proceso histórico de largo plazo en las narrativas actuales (Briones, 1994: 121). La fuerza explicativa en la conformación de la actual comunidad Ñorquinco está en su historia y en su relación con Parques.

Me gustaría cerrar con un breve recuerdo producto de mis idas y vueltas a la región. En 2015 estuve en Aluminé con motivo de presentar mi tesis de doctorado. Siendo una tesis que cruzó a muchas familias, tuve la suerte de tener un público muy diverso. Al finalizar la exposición pudimos dialogar observando puntos de interés. Finalizado el evento ya fuera de la Biblioteca Popular Juan Benigar, lugar del encuentro, una mujer mapuche me dice, "toda mi familia estaba ahí"; en referencia a las fichas [...] "contaba mi mamá que se vino de a pie a Aluminé, nunca fueron al Anexo [...] los sacaron como perros [...] y también estaban los [...]" y comenzó a mencionar diferentes familias expulsadas. La memoria convierte el tiempo y el espacio en construcciones afectivas, tensionadas a partir de conflictos y agencias presentes y potencialidades futuras (Rodríguez, 2004; Trentini, 2011) en un contexto determinado que no fue elegido por los propios participantes (Briones, 1994: 111). Analizar prácticas posgenocidas es pensar en el tipo especial de sociedad que se construyó en nombre de una identidad excluyente, la Argentina 
3. Me gustaría remontarme a la definición de las Naciones Unidas (1948) que sustancializa este crimen a partir de la intencionalidad y sistematicidad en la destrucción de un grupo -definido por su condición racial, nacional, étnica o religiosa- a través de acciones que van desde la eliminación física hasta generar condiciones de muerte, pasando por el daño mental, psicológico, torturas y el secuestro de niños del grupo víctima al grupo victimario. En cualquiera de los casos -con excepción de las definiciones que impiden ver otros genocidios por fuera del Holocausto- las prácticas genocidas aplican al proceso histórico que vivieron las parcialidades indígenas en nuestro país. Para profundizar temáticas específicas al proceso de expansión estatal y las prácticas genocidas del estado argentino para con población originaria recomendamos: Nagy y Papazian (2011), Lenton (2014: 32-51), Mapelman (2015), Delrio et al. (2018), entre otros. (En página 82).

\section{Abreviaturas utilizadas}

》Administración de Parques nacionales (APN)

» Archivo de la Dirección Provincial de Catastro (ADPC)

»Archivo General de la Nación (AGN)

» Comisión Nacional de Zonas de Seguridad (CNZS)

» Diario de Sesiones de la Cámara de Diputados (CSCD)

»Diario de Sesiones de la Cámara de Senadores (DSCS)

»Parque Nacional Lanín (PNL)

"Permisos Precarios de Ocupación y Pastoreo (PPOP) 


\section{Q Bibliografía}

» Bessera, E. (2011). “La Nacionalización de las fronteras patagónicas. Los parques nacionales como herramienta estatal de ocupación e integración territorial” en Valverde, S.; Maragliano, G.; Impemba, M. y F. Trentini (coords.), Procesos históricos, transformaciones sociales y construcciones de fronteras. Aproximaciones a las relaciones interétnicas. Estudios sobre norpatagonia, Argentina y Labrador, Canadá: 67-106. Buenos Aires, Facultad de Filosofía y Letras (FFyL), Universidad de Buenos Aires (UBA).

» Bjornlund, M.; Markusen, E. y M. Mennecke (2005). “¿Qué es un genocidio?” en Feierstein, D. (comp.), Genocidio, la administración de la muerte en la modernidad: 17-48. Buenos Aires, EDUNTREF.

» Briones C. (1994). “Con la tradición de las generaciones pasadas gravitando sobre la mente de los vivos: Usos del Pasado e invención de la tradición”. Runa. XXI: 99-130.

» Brow, J. (1990). Notes on Community, Hegemony, and the Uses of the Past. Anthropological Quarterly 63 (1): 1- 6.

" Carpinetti, B. (2004). Derechos indígenas en el Parque Nacional Lanín. De la expulsión al co-manejo. Buenos Aires, APN.

»Deleuze G. y F. Guattari (1997). Mil Mesetas. Capitalismo y Esquizofrenia. Valencia, PreTextos.

»Delrio, W. (2005). Memorias de expropiación. Sometimiento e incorporación indígena en la Patagonia (1872-1943). Buenos Aires, Ed. UNQ.

» Delrio, W; Escolar, D; Lenton, D; Pérez, P. y M. Malvestitti (2018). “Introducción” en Delrio, W; Escolar, D; Lenton, D; Pérez, P. y M. Malvestitti (comps.), En el país de nomeacuerdo. Archivos y memorias del genocidio del Estado argentino sobre los pueblos originarios, 1870-1950: 9-19. Viedma, Editorial UNRN.

»Escolar, D. y L. Saldi (2018). “Cartas invisibles de la nueva nación. Los prisioneros indígenas de la Campaña del Desierto en el registro parroquial de Mendoza” en Delrio, W; Escolar, D; Lenton, D; Pérez, P. y M. Malvestitti (comps.), En el país de nomeacuerdo. Archivos y memorias del genocidio del Estado argentino sobre los pueblos originarios, 18701950: 99-136. Viedma, Editorial UNRN.

» Feierstein, D. (2007). El Genocidio como práctica social. Entre el nazismo y la experiencia argentina. Buenos Aires, Fondo de Cultura Económica.

» Figuerero, J. T. (1945). Historia Militar de los Regimientos Argentinos. Buenos Aires, Artes Gráficas Modernas

» Grossberg, L. (1992). “Power and Daily Life” en We Gotta Get Out of This Place. Popular Conservatism and Postmodern Culture: 89-112 New York, Routledge.

» Haesbaert, R. ([1990] 2011). El mito de la desterritorialización. Del "fin de los territorios" a la multiterritorialidad. México, Ed. Siglo XXI.

» Hall, S. (1986). Gramsci's Relevance for the Study of Race and Ethnicity. Journal of Communication Inquiry 10: 5-27. Londres, Open University Press.

» Harvey, D. ([1990] 2012). La condición de la posmodernidad. Investigación sobre los orígenes del cambio cultural. Buenos Aires, Amorrortu.

» Lefebvre, H. ([1974] 2008). The production of the Space. Malden, Blackwell Publishing.

» Lenton, D. (2014). “Nuevas y viejas discusiones en torno a la aplicabilidad del concepto de 
genocidio en la historia de las relaciones entre el genocidio y los pueblos originarios" en Lanata, J. L. (comp.), Prácticas genocidas y violencia estatal en perspectiva transdisciplinar: 32-51. Bariloche, IIDYPCA.

»Lenton, D. (2017). La criminalización de los mapuche. El nuevo enemigo público Revista Anfibia: s/d. Buenos Aires, UNSAM. Disponible en Internet: http://revistaanfibia.com/ ensayo/nuevo-enemigo-publico/. Consultado el: 12 de marzo de 2018.

» Mapelman, V. (2015). Octubre Pilagá Memorias y archivos de la masacre de La Bomba. Buenos Aires, Tren en Movimiento.

» Moreno, F. ([1897] 2004). Apuntes preliminares sobre una excursión a los territorios del Neuquén, Río Negro, Chubut y Santa Cruz. Buenos Aires, El Elefante Blanco.

» Muzzopappa, E. (2000). “Metáforas estratégicas. El concepto de cultura en y sobre el ámbito de la seguridad”. Tesis de licenciatura en Ciencias. Antropológicas, FFyL, UBA. Disponible en Internet: http://antropologia.filo.uba.ar/sites/antropologia.filo.uba. ar/files/documentos/Muzzopappa\%20-\%20Tesis\%20200o.pdf. Consultado el: 17 de diciembre de 2017.

» Naciones Unidas (1948). Asamblea General de las Naciones Unidas. Convención para la prevención y la sanción del delito de genocidio. Disponible en Internet: https://www. un.org/en/genocideprevention/documents/Appeal-Ratification-Genocide-FactSheetSP.PDF. Consultado el: 10 de abril de 2018.

» Nagy, M. y A. Papazian (2011). El campo de concentración de Martín García. Entre el control estatal dentro de la isla y las prácticas de distribución de indígenas (1871-1886). Corpus. Archivos virtuales de la alteridad americana 1 (2): 1-22 Disponible en Internet: http://ppct.caicyt.gov.ar/index.php/corpus/article/view/392. Consultado el: 9 de octubre de 2017.

"Papazian, A. (2009). Pulmarí. Representaciones territoriales. ¿Para quién? Revista Espacios de crítica y producción 40:32-39. Buenos Aires, FFyL, UBA.

»Papazian, A. (2011a). "Memorias vividas y Olvidos históricos en territorios conflictivos. Devenir Mapuche- Devenir Pulmarí- Devenir Mapu(winka)che”. Ponencia presentada en las XIII Jornadas Interescuelas Departamentos de Historia. Departamento de Historia, Universidad Nacional de Catamarca, 10 al 13 de agosto.

» Papazian, A. (2011b). “Memorias Mapuche en torno a prácticas de despojo e invisibilización (1947-1953) (2008-2010)" ponencia presentada en el IV Seminario internacional de políticas de la memoria. Centro cultural de la memoria Haroldo Conti, Buenos Aires, 29 de septiembre al 1 de octubre.

" Papazian, A. (2013). “El territorio también se mueve: relaciones sociales, historias y memorias en Pulmarí (1880-2006)." Tesis doctoral. FFyL, UBA. Disponible en Internet http://repositorio.filo.uba.ar/handle/filodigital/1658. Consultado el: 15 de agosto de 2018.

» Papazian, A. (2018) Pliegues genocidas en Estados nacientes: el genocidio armenio en Turquía y el genocidio indígena en Argentina. Revista Estudios sobre Genocidios 9. (13): 11-26. Disponible en Internet: http://www.revistasuntref.com.ar/index.php/reg/article/ view/255/235. Consultado el: 17 de marzo de 2018.

» Pérez, P. (2016). Archivos del Silencio. Estado, Indígenas y violencia en Patagonia Central, 1878-1941. Buenos Aires, Prometeo.

»Ramos, A. (2010). Los pliegues del linaje. Memorias y políticas Mapuches-Tehuelches en contextos de desplazamiento. Buenos Aires, EUDEBA.

»Rodríguez, L. (2004). Reflexiones acerca de la memoria y los usos del pasado a partir del análisis de un caso en el Noroeste argentino: Departamento de Santa María. Cuadernos 
de Antropología Social 20: 151-168.

» Sack, R. (1983). Human Territoriality: A Theory. Annals of Association of American Geographers 73 (1): 55-74.

" Tozzini, A. (2011). "Pagarnos con lo propio. Trayectorias comunes en territorios desgajados” en Valverde, S; Maragliano, G; Impemba, M. y F. Trentini (coords.), Procesos históricos, transformaciones sociales y construcciones de fronteras. Aproximaciones a las relaciones interétnicas. Estudios sobre Norpatagonia, Argentina y Labrador: 275-305. Buenos Aires, FFyL, UBA.

»Trentini. F. (2011). “La 'otra historia': la importancia de la memoria en la construcción del pasado” en Valverde, S.; Crosa, Z.; González Palominos, K. y P. Tato Vázquez (comps.), El Lof Ñorquinco y la historia de sus pobladores: de la Expulsión a la reconstrucción: 161-194. Buenos Aires, FFyL, UBA.

"Valverde, S. (2009). Identidad étnica, etnicidad y reorganización comunitaria: el caso de la agrupación Mapuche Ñorquinco (provincia de Neuquén). Papeles de trabajo 17: 74-90. Rosario, Centro de Estudios Interdisciplinarios.

» Valverde, S.; García, A. y L. Bersten (comps.) (2008). Relatos patagónicos. Historias familiares en la construcción del espacio social en Villa Traful. Buenos Aires, FFyL, UBA

»Villegas, C. ([1881-1883] 1977). Expedición al Gran Lago Nahuel Huapi en el año 1881. Partes y Documentos Relativos. Buenos Aires, Eudeba. 